\title{
Increase in skeletal muscle fatty acid binding protein (FABPC) content is directly related to weight loss and to changes in fat oxidation following a very low calorie diet
}

\author{
E. E. Blaak ${ }^{1}$, J.F.C. Glatz ${ }^{2}$, W.H. M Saris ${ }^{1}$ \\ ${ }^{1}$ Department of Human Biology, Nutrition Research Centre, Maastricht University, Maastricht, \\ The Netherlands \\ ${ }^{2}$ Department of Physiology, Maastricht University, Maastricht, The Netherlands
}

\section{Abstract}

Aims/hypothesis. There is increasing evidence that intracellular fatty acid binding proteins (FABPc's; 15 $\mathrm{kD})$ function as vehicles of cytosolic fatty acid transport. We studied skeletal muscle cytosolic FABPc, and enzymes reflecting $\beta$-oxidation and oxidative capacity (3-hydroxyacyl-CoA dehydrogenase, HAD, and citrate synthase, CS) in relation to weight loss and changes in substrate utilisation in a group of 35 obese women and obese men with Type II (non-insulin-dependent) diabetes mellitus (women $=27$, men $=8$ ).

Methods. Muscle biopsies (vastus lateralis), and measurements of body composition, resting energy expenditure and respiratory exchange ratio were taken before and after dietary intervention (by means of a very low calorie diet).

Results. Muscle FABPc tended to increase after diet $\left(178 \pm 13\right.$ vs $\left.204 \pm 12 \mathrm{mg} \cdot \mathrm{gww}^{-1}, p=0.06\right)$, whereas there were no changes in CS $(10.5 \pm 0.7$ vs $11.1 \pm 0.6$
$\left.\mathrm{U}^{\mathrm{gww}} \mathrm{gw}^{-1}\right)$ and $\mathrm{HAD}(11.2 \pm 0.7$ vs $11.7 \pm 0.6$

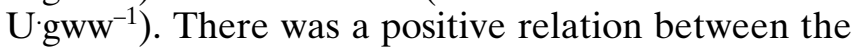
increase in FABPc as result of diet and the amount of weight lost $\left(p<0.01\right.$; adjusted $\left.\mathrm{R}^{2}, 15.4 \%\right)$, even when adjusted for mean body weight, and changes in $\mathrm{CS}$ and in HAD by partial regression analysis. Interestingly, the increase in FABPc was positively related to increases in resting fat oxidation (adjusted $\mathrm{R}^{2}$, $24 \%$ ), even when adjusted for mean resting fat oxidation, and changes in CS and in HAD.

Conclusion/interpretation. In conclusion, the ability to increase muscle FABPc could be directly related to weight loss and to changes in fat oxidation following dietary intervention in obesity and Type II (noninsulin-dependent) diabetes mellitus. [Diabetologia (2001) 44: 2013-2017]

Keywords Cytosolic fatty acid binding proteins, skeletal muscle, fat oxidation, weight loss, obesity, Type II diabetes mellitus.
The prevalence of obesity and obesity-associated Type II (non-insulin-dependent) diabetes mellitus is rapidly increasing in Western societies. This has led to a new focus on dieting and weight loss. The

Received: 4 May 2001 and in revised form: 17 July 2001

Corresponding author: E. E. Blaak, Department of Human Biology, Nutrition Research Centre, Maastricht University, P. O. Box 616, 6200 MD Maastricht, The Netherlands

E-mail: E.Blaak@HB. Unimaas.nl

Abbreviations: FABPc, Cytosolic (intracellular) fatty acid binding protein; HAD, 3-hydroxyacyl-CoA dehydrogenase; CS, citrate synthase; CD36/FAT, fatty acid translocase amount of weight and fat loss varies among individuals in the same weight-loss regime. This variation between individuals has been shown to be related to adherence, initial body weight, total energy expenditure and substrate utilisation $[1,2]$. In particular, a reduced reliance on lipid oxidation has been identified as a risk factor for weight gain [3] and weight regain after weight loss [4]. This raises the possibility that the capacity to increase fat oxidation following dietary intervention could also be a determining factor for the success of weight loss programmes.

There is abundant indirect and direct evidence that FABPc's (14-15 kDa) serve as carriers of intracellular NEFA through the cytoplasm, thereby influ- 
encing their overall rate of utilisation $[5,6]$. Recently, it was shown that mice lacking heart-type FABP $(\mathrm{H}-$ FABP) show a severe defect in peripheral (non-hepatic, non-fat) NEFA utilisation, indicating a physiologically important role for FABPc' $s$ in fat metabolism [7]. These findings suggest that FABPc could be involved in the changes in fat oxidation following dietary intervention.

Thus, the increasing evidence for a physiologically important role for FABPc in (disturbances of) human fatty acid utilisation has prompted the present analysis of the relation between muscle FABPc content, weight loss and changes in substrate utilisation in a group of 35 subjects from the previous studies combined $[8,9]$. This analysis made it possible to adjust changes in FABPc for simultaneous changes in oxidative capacity and capacity for $\beta$-oxidation. Our data give the first clear indication that the capacity to increase muscle FABPc is directly related to the amount of body weight lost and to the ability to increase or maintain fat oxidation after diet.

\section{Subjects and methods}

Patients were 27 obese women and 8 obese men recently diagnosed as having Type II diabetes from previous studies in our laboratory $[8,9]$. Their characteristics are indicated in Table 1. All women were premenopausal. The Type II diabetic patients were treated with diet alone $(n=3)$ or diet together with sulphonylureas $(n=5)$. Blood glucose lowering medication was stopped two days before the experiments, during the whole diet period and after diet measurements. No other medication was used. None of the patients had serious health problems apart from obesity or diabetes. A normal resting ECG was a prerequisite for participation. All subjects engaged no more than $3 \mathrm{~h}$ a week in sports, and none had a physically demanding job. The study protocol was approved by the Medical Ethical Review Committee of Maastricht University. Informed written consent was obtained from all subjects.

Experimental design. The experimental design has, previously been described in detail $[8,9]$. Briefly, before the start of a 8-10 week diet period, body composition, maximal aerobic power resting and exercise-induced energy expenditure and markers of NEFA transport and oxidation in muscle biopsies were measured. On a separate occasion, needle muscle biopsies were taken percutaneously from the vastus lateralis muscle after an overnight fast, using the Bergström method with suction [10]. The biopsies were immediately frozen in liquid nitrogen and stored at $-80^{\circ} \mathrm{C}$ until the determination of the activities of mitochondrial enzymes, and cytosolic FABP. Measurements were repeated at the end of the 8-week diet period when energy restrictive conditions were still maintained or at the end of week 10 after having returned to a normal diet for 2 weeks.

Diet period. The total diet intervention period lasted 8-10 weeks. During the first 4 weeks of the diet period the patients followed a very low calorie diet (Modifast, Novartis Nutrition, Breda, The Netherlands) of $2 \mathrm{MJ} /$ day, which provided (in $\mathrm{g} /$ day) $52 \mathrm{~g}$ protein, $50 \mathrm{~g}$ carbohydrate, $7 \mathrm{~g}$ fat, $1.3 \mathrm{~g}$ sodium and a micronutrient content which meets the Dutch recommended daily allowances. In week five patients were allowed
Table 1. Descriptive data of the subjects (27 F, 8 M)

\begin{tabular}{lcc}
\hline Variables & Before diet & After diet \\
\hline Age & $40.5 \pm 9.5$ & \\
Weight $(\mathrm{kg})$ & $92.2 \pm 15.7$ & $80.2 \pm 13.4^{\mathrm{b}}$ \\
BMI $\left(\mathrm{kg} / \mathrm{m}^{2}\right)$ & $32.4 \pm 3.9$ & $28.2 \pm 3.5^{\mathrm{b}}$ \\
$\%$ Body fat & $40.2 \pm 4.7$ & $34.8 \pm 5.9^{\mathrm{b}}$ \\
WHR & $0.86 \pm 0.06$ & $0.85 \pm 0.08$ \\
REE $\left(\mathrm{k} \mathrm{J} . \mathrm{kgFFM}^{-1} \cdot \mathrm{min}^{-1}\right)$ & $0.094 \pm 0.011$ & $0.092 \pm 0.012$ \\
Resting fat oxidation & & \\
$(\mathrm{mg} / \mathrm{kg}$ & & $1.33 \pm 0.30$ \\
Glucose $(\mathrm{mmin})$ & $1.41 \pm 1.01$ & $4.90 \pm 0.15^{\mathrm{a}}$ \\
NEFA $(\mu \mathrm{mol} / \mathrm{l})$ & $5.27 \pm 0.19$ & $568 \pm 33$ \\
\hline
\end{tabular}

Means \pm SEM; Student's paired $t$-test: ${ }^{\mathrm{a}} p<0.01,{ }^{\mathrm{b}} p<0.001$

to replace one sachet each day with an energy restricted meal (dinner), which was increased to two energy restricted meals a day in week 6 . In week 7 and 8 patients consumed an energy restricted diet of 3.5-4.2 MJ/day. During week 9 to 10 patients were in weight stable conditions.

Body composition. Body weight was determined on an electronic scale, accurate to $0.1 \mathrm{~kg}$. Waist and hip circumference measurements to the nearest $1 \mathrm{~cm}$ were made with the subjects standing upright. Body composition was determined by hydrostatic weighing with simultaneous lung volume measurement (Volugraph 2000, Mijnhardt, Breda, The Netherlands). Body composition was calculated according to Siri [11].

Resting energy expenditure. During the resting period and during exercise, $\mathrm{O}_{2-}$ and $\mathrm{CO}_{2}$ - exchange were determined by means of an open circuit spirometry (Oxycon Beta, Mijnhardt, Breda, The Netherlands), Values for energy expenditure and respiratory exchange ratio were averaged over the last $20 \mathrm{~min}$ of the resting period. The metabolic rate was calculated from oxygen consumption and carbon dioxide (VO2 and $\mathrm{O} 2$ ) according to the equation of Weir [12]. Carbohydrate and fat oxidation rates were calculated from $\mathrm{VO} 2$ and $\mathrm{VCO} 2$ and urinary nitrogen excretion [13].

Biochemical methods. The muscle biopsies were homogenized in ice-cold tris-EDTA buffer at $\mathrm{pH}$ 7.4. The homogenates were subsequently sonicated for $4 \cdot 15 \mathrm{~s}$ and centrifuged at $10000 \mathrm{~g}$ for $2 \mathrm{~min}$ at $4{ }^{\circ} \mathrm{C}$ to remove cell debris. Tissue content of hearttype (or muscle-type) cytosolic fatty acid binding protein (FAB$\mathrm{Pc}$ ) in skeletal muscle was measured by means of a newly developed ELISA (Hycult Biotechnology, Uden, Netherlands), using recombinant human FABP as standard [14]. Citrate synthase (CS) was determined according to the method of Sherpherd and Garland [15], whereas 3-hydroxyacyl-CoA dehydrogenase (HAD) was assaysed according to Bergmeyer [16].

Statistical analyses. Data are presented as means \pm SEM. Values before and after diet were compared using a Students' paired $t$ test. To analyse the relation between changes in muscle characteristics and changes in body composition and substrate utilisation, a partial regression analysis was used. Because the initial magnitude of a variable can be automatically related to the magnitude of change in this variable as a result of intervention, an artificial correlation can be obtained. For this reason the magnitude of a variable was defined as the average variable before and after diet (for body weight and fat oxidation, see 17). A $p$ value of less than 0.05 was considered to be statistically significant. 


\section{Results}

Body composition and energy metabolism. Diet significantly reduced body weight (on average $12 \mathrm{~kg}$, $p<0.001$; Table 1), which can be accounted for $65 \%$ by loss of fat mass and by $35 \%$ by loss of fat free mass. Resting energy expenditure and basal fat oxidation (expressed as fat free mass) did not change as result of diet.

Subgroup characteristics. The total subject group can be divided into two subgroups: an obese diabetic group of men $(n=8)$, and an obese group of women $(n=27)$, studied under weight-table and energy-restricted conditions, respectively. Individual values for weight loss and resting fat oxidation of the two different subgroups are indicated in Figures 1 and 2. As expected, glucose concentrations were higher in obese diabetic patients $(n=8$, on average: $7.70 \pm 1.2 \mathrm{mmol} / \mathrm{l}$, range $5.5-9.2 \mathrm{mmol} / \mathrm{l}$ ) than in the obese patients $(4.74 \pm 0.42 \mathrm{mmol} / 1$, range $4.2-5.7 \mathrm{mmol} / \mathrm{l})$. In both groups there was a significant decrease in glucose concentrations as result of diet $(p<0.001)$. Resting NEFA concentrations decreased in the obese diabetic group $(743 \pm 251$ vs $527 \pm 334 \mu \mathrm{mol} / 1, p<0.05)$, whereas there was no change in the obese group $(524 \pm 245$ vs $645 \pm 270 \mu \mathrm{mol} / \mathrm{l})$.

Muscle characteristics. Muscle FABPc tended to increase as result of diet $(178 \pm 81$ vs $204 \pm 126 \mathrm{mg} / \mathrm{g}$ ww $p=0.06)$, whereas there were no changes in citrate synthase $(\mathrm{CS}, 10.5 \pm 4.0$ vs $11.1 \pm 5.1 \mathrm{U} / \mathrm{gww})$ and 3-hydroxyacylCoA dehydrogenase (HAD, $11.2 \pm 4.2 \mathrm{vs} 11.7 \pm 5.8 \mathrm{U} / \mathrm{gww}$ ) as a result of diet.

Subgroups analysis. In the above-mentioned two subgroups, there was a tendency towards an increase in FABPc (obese patients: $172 \pm 63$ vs $216 \pm 114 \mathrm{mg} / \mathrm{g}$ ww $p=0.06$, obese Type II diabetic patients $147 \pm 112$ vs $195 \pm 70 \mathrm{mg} / \mathrm{g} \mathrm{ww}, p=0.06)$. There were no changes in CS and HAD in both groups as result of diet.

Partial regression analyses. There was a positive relation between the absolute increase in muscle FABPc content as result of diet and the amount of body weight lost ( $p<0.01$, adjusted $\mathrm{R}^{2} 15.4 \%$, Fig 1$)$. This relation was also found in the subgroup of obese women $\left(p<0.05\right.$, adjusted $\left.\mathrm{R}^{2} 15.7 \%\right)$ and in the subgroup of obese diabetic men $\left(p<0.01\right.$, Adjusted $\mathrm{R}^{2}$ is $78 \%$ ). When adjusted for mean body weight (see under statistical analyses) the correlation in the total group persisted (partial correlation $0.40, p<0.05$, Table 2). Furthermore, a correction for changes in oxidative capacity ( $\Delta$ citrate synthase) and changes in capacity for $\beta$-oxidation ( $\triangle \mathrm{HAD}$ ) in the total group still yields a significant relation between $\triangle \mathrm{FABPc}$

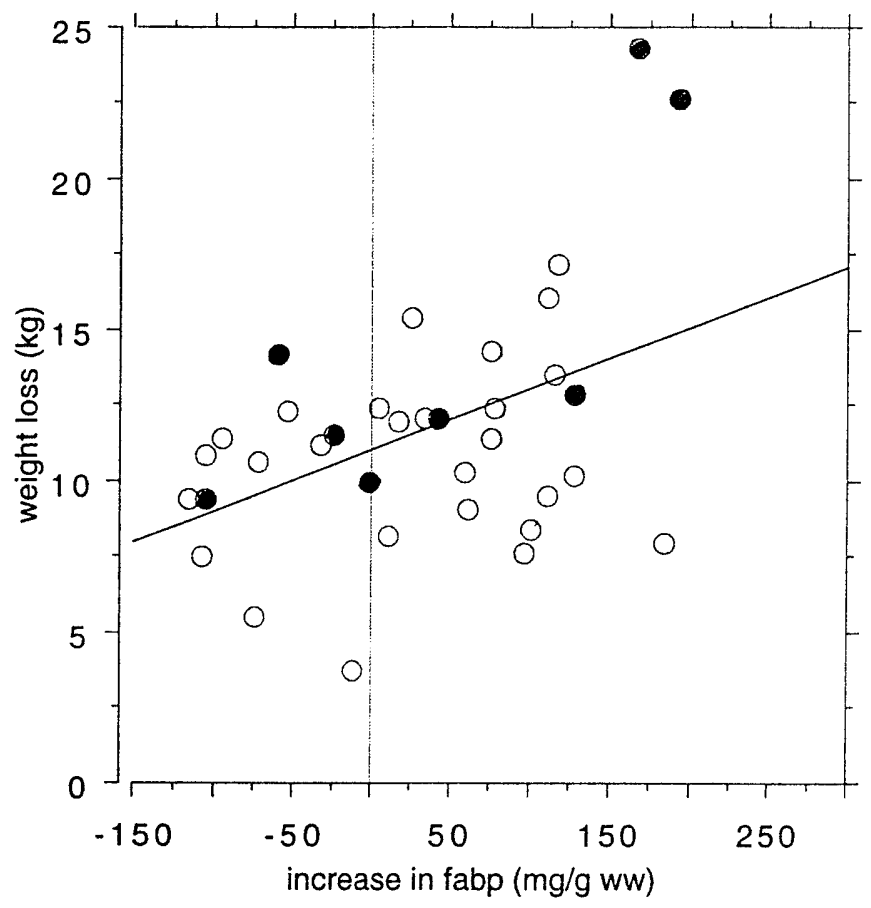

Fig. 1. Relationship between the increase of FABPc and the amount of weight loss as a result of diet in obese and obese Type II diabetic patients $\bigcirc$, obese diabetic men studied under 'weight stable' conditions; $\bigcirc$, obese women studied under 'energy-restricted' conditions

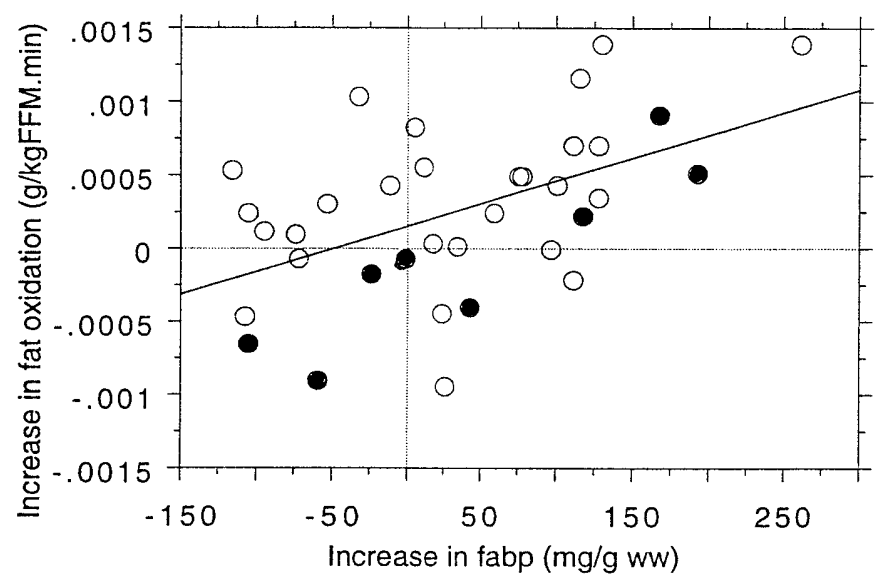

Fig. 2. Relationship between the increase in FABPc and the increase in resting fat oxidation $\mathbf{O}$, obese diabetic men studied under 'weight stable' conditions, $\bigcirc$, obese women studied under 'energy restricted' conditions

and $\Delta$ body weight (Table 2 ). There was no relation between the initial level of FABPc and changes in body weight loss.

Interestingly, the increase in FABPc was positively related to the increase in resting fat oxidation (adjusted $\mathrm{R}^{2} 24 \%$, Fig 2), also when adjusted for mean level of Fatoxidation $(p<0.01)$ or for changes in oxidative capacity $(\triangle \mathrm{CS})$ and changes in capacity for $\beta$-oxidation (Table 3 ). The relation between changes in FAB- 
Table 2. Partial correlation coefficients between changes in body weight and changes in FABPc and mean body weight (upper part), or changes in HAD, and CS (below)

\begin{tabular}{ll}
\hline & $\Delta$ Body weight $(\mathrm{kg})$ \\
\hline$\Delta$ FABP $\left(\mathrm{mg}^{\circ} \mathrm{g} \mathrm{ww}^{-1}\right)$ & $0.40^{\mathrm{a}}$ \\
Mean level of body weight $(\mathrm{kg})$ & $0.52^{\mathrm{b}}$ \\
$\Delta \mathrm{FABP}\left(\mathrm{mg} \cdot \mathrm{g} \mathrm{ww}^{-1}\right)$ & $0.39^{\mathrm{a}}$ \\
$\Delta \mathrm{HAD}\left(\mathrm{U} \cdot \mathrm{g} \mathrm{ww}^{-1}\right)$ & 0.13 \\
$\Delta \mathrm{CS}\left(\mathrm{U} \cdot \mathrm{g} \mathrm{ww}^{-1}\right)$ & 0.05 \\
\hline
\end{tabular}

${ }^{\mathrm{a}} p<0.05 ;{ }^{\mathrm{b}} p<0.01$

Table 3. Partial correlation coefficients between changes in resting fat oxidation and changes in FABPc and mean fat oxidation (upper part) or changes in HAD, and CS (below)

\begin{tabular}{ll}
\hline & $\begin{array}{l}\Delta \text { fat oxidation } \\
\left(\mathrm{mg} / \mathrm{kg}_{\mathrm{FFM}} \cdot \mathrm{min}\right)\end{array}$ \\
\hline$\Delta \mathrm{FABP}\left(\mathrm{mg} \cdot \mathrm{g} \mathrm{ww}^{-1}\right)$ & $0.51^{\mathrm{a}}$ \\
Mean level of fat oxidation & 0.01 \\
$\Delta \mathrm{FABP}\left(\mathrm{mg} \cdot \mathrm{g} \mathrm{ww}^{-1}\right)$ & $0.38^{\mathrm{a}}$ \\
$\Delta \mathrm{HAD}\left(\mathrm{U} \cdot \mathrm{g} \mathrm{ww}^{-1}\right)$ & 0.01 \\
$\Delta \mathrm{CS}\left(\mathrm{U} \cdot \mathrm{g} \mathrm{ww}^{-1}\right)$ & 0.04 \\
\hline
\end{tabular}

${ }^{\mathrm{a}} p<0.05 ;{ }^{\mathrm{b}} p<0.01$

Pc expression and increase in resting fat oxidation was also present in the two subgroups (obese, $p<0.05$, adjusted $\mathrm{R}^{2} 12.4 \%$, and obese diabetic $p<0.01$, adjusted $\left.\mathrm{R}^{2}: 75.2 \%\right)$

\section{Discussion}

Cytosolic fatty acid binding proteins are a genetically related family of fatty acid transport proteins which are now accepted to be mediators of intracellular NEFA transport and utilisation $[5,6]$. It has recently been reported that mice lacking heart-type FABPc have a severe defect in peripheral NEFA utilisation, supporting a role for FABPc's in NEFA utilisation [7]. Our data indicate that the capacity to increase muscle FABPc is directly related to the amount of body weight lost and to the capacity to increase or maintain fat oxidation after diet in obese and obese Type II diabetic patients.

Several mechanisms could explain the above described relation. Firstly, it is tempting to speculate that the capacity to increase fatty acid transport capacity could determine the amount of weight loss as result of diet, as this would increase or maintain the capacity for fat oxidation. That FABPc is a determining step in fat oxidation is supported by the finding that the relation between FABPc expression and fat oxidation is independent from changes in oxidative capacity (citrate synthase) and capacity for beta-oxidation (HAD). On the other hand, because our data are correlational in nature, we cannot entirely exclude that changes in FABPc expression are second- ary to the metabolic changes during and after weight loss.

Furthermore, the membrane-associated fatty acid transporter fatty acid translocase (FAT/CD36, $88 \mathrm{kD}$ ) seemed to be markedly up-regulated together with FABPc in cardiac muscle of insulin deficient rats [18], indicating the possibility that not only FABPc but also the plasma membrane bound fatty acid transporters like CD36/FAT could be related to weight loss and changes in fat oxidation. Interestingly, a genetic mutation in the $C D 36 / F A T$ gene, resulting in CD36/FAT deficiency, has been shown to be associated with severe defects in heart NEFA utilisation in human beings [19]. Further studies are necessary to clarify whether cytosolic fatty acid binding proteins are limiting or adaptive proteins in human muscle fat oxidation. This is especially important for Type II diabetic patients where defects in NEFA utilisation could cause skeletal muscle insulin resistance [20, 21, 22].

A drawback of our study is that the present data analysis is based on two different subgroups: the obese women were studied during energy restricted conditions and the diabetic men after having returned to normal diet for a period of two weeks. However, an analysis of the relation between FABPc, and weight loss and basal fat oxidation in the two subgroups gave similar results. Thus, we have no indications that the combination of both groups for the regression analysis could have affected our conclusions.

In summary, the ability to increase muscle FABPc during weight loss was strongly related to the amount weight loss and to the ability of muscle to increase fat oxidation after dietary intervention in obesity and Type II diabetes mellitus. It remains to be determined whether these findings represent a causal relation between FABPc, weight loss and changes in fat oxidation or whether FABPc expression is merely an adaptive response to the metabolic changes during or after weight loss. Our findings underscore a physiologically important role for FABPc in the transport and utilisation of NEFA in human beings.

Acknowledgements. This work was supported by a grant from the Dutch Diabetes Research Foundation and the Netherlands Organisation of Scientific Research

\section{References}

1. Kreitzman SN, Coxon AY, Johnson PG, Ryde SJS (1992) Dependence of weight loss during very-low calorie diets on total energy expenditure rather than on resting metabolic rate, which is associated with fat free mass. Am J Clin Nutr 56: 258S-261S

2. Prentice AM, Goldberg GR, Jebb SA, Black AE, Murgatroyd PR (1991) Physiological responses to slimming. Proc Nutr Soc 50: 441-458

3. Zurlo F, Lillioja S, Esposito-Del Puente A, Nyomba BL, Raz I, Saad MF, et al (1990) Low ratio of carbohydrate to 
fat oxidation as predictor of weight gain: study of $24 \mathrm{~h} R Q$. Am J Physiol 259: E650-7

4. Ranneries C, Bülow J, Buemann B, Christensen NJ, Madsen J, Astrup A (1998) Fat metabolism in formerly obese women. Am J Physiol 274: E155-E161

5. Glatz JFC, van der Vusse GJ (1996) Cellular fatty acid binding proteins: their function and physiological significance. Prog Lipid Res 35: 243-282

6. Storch J, Thumser EA (2000) The fatty acid transport function of fatty acid-binding proteins. Biochim Biophys Acta 1486: 28-44

7. Binas B, Danneberg H, McWhir J, Mullins L, Clark AJ (1999) Requirement for the heart-type fatty acid binding protein in cardiac fatty acid utilization. Faseb J 13: 805-812

8. Kempen KPG, Saris WHM, Kuipers H, Glatz JFC, van der Vusse, GJ (1998) Skeletal muscle characteristics before and after energy restriction in human obesity: fibre type, enzymatic $\beta$-oxidative capacity and fatty acid binding protein content. Eur J Clin Invest. 28: 1030-1037

9. Blaak EE, Wolffenbuttel BHR, Saris WHM, Pelsers MMAL, Wagenmakers AJM (2001) Weight reduction and the impaired plasma-derived FFA oxidation in type 2 diabetic subjects. J Clin Endocrinol Metab 86: 1638-1644

10. Evans WJ, Phinney SD, Young VR (1982) Suction applied to a muscle biopsy maximizes sample size. Med. Sci. Sports Exer. 14: 101-102

11. Siri WE (1956) The gross composition of the body. Adv in Biol Med Physiol 4, 239-280

12. Weir JB (1949) New methods for calculating metabolic rate with special reference to protein metabolism. J Physiol 109: 1-9

13. Frayn KN (1983) Calculation of substrate oxidation rates in vivo from gaseous exchange. J Appl Physiol 55: 628-634

14. Wodzig KWH, Pelsers MMAL, van der Vusse GJ, Roos W, Glatz JFC (1997) One-step enzyme linked immunosorbent assay (ELISA) for plasma fatty acid-binding protein. Ann. Clin. Biochem. 34: 263-268

15. Shepherd D, Garland PB (1969) Citrate synthase from the rat liver. Meth. Enzymol. 13: 11-16

16. Bergmeyer HU(1974) Methods of enzymatic analysis, vol 1. Academic Press, New York, pp 474-476; 480-482

17. Bland JM, Altman DG (1986) Statistical methods for assessing agreement between two methods of clinical measurement. Lancet 1: 307-310

18. Pelsers MMAL, Lutgerink J, van Nieuwenhoven FA, Tandon NN, van der Vusse GJ, Arends JW, et al (1999) A sensitive immunoassay for rat fatty acid translocase (CD36) using phage antibodies selected on cell transfectants: abundant presence of fatty acid translocase/CD36 in cardiac and red skeletal muscle and up-regulation in diabetes. Biochem J 337: 407-414

19. Nozaki S, Tanaka T, Yamashita S, Sohmiya K, Yoshizumi T, Okamoto F, et al. (1999)CD36 mediates long chain fatty acid transport in human myocardium: complete myocardial accumulation defect of radiolabeled long chain fatty acid analogue in subjects with CD36 deficiency. Mol Cell Biochem 192: 129-35

20. Kelley DE, Goodpaster B, Wing RR, Simoneau JA (1999) Skeletal muscle fatty acid metabolism in association with insulin resistance, obesity and weight loss. Am J Physiol 277: E1130-E1142

21. Blaak EE, Wagenmakers AJM, Glatz JFC, Wolffenbuttel BHR, Kemerink GJ, Langenberg CJM, et al. (2000) Plasma free fatty acid utilisation and fatty acid binding protein content are diminished in forearm skeletal muscle of type 2 diabetic subjects. Am J Physiol 279:E146-E154

22. Blaak EE, van Aggel-Leijssen DPC, Wagenmakers AJM, Saris WHM, van Baak MA (2000) Impaired oxidation of plasma-derived fatty acids in type 2 diabetic subjects during moderate-intensity exercise. Diabetes 49: 2101-2107 